\title{
A New Species of the Genus Penares (Demospongiae: Astrophorida: Ancorinidae) from Korea
}

\author{
Yong Jin Jeon and Chung Ja Sim* \\ Department of Biological Sciences, College of Life Sciences and Nano Technology, \\ Hannam University, Daejeon 305-811, Korea
}

\begin{abstract}
A new marine sponge in the family Ancorinidae, Penares hongdoensis n. sp. was collected from Hongdo Island, Korea by SCUBA diving in 2004. P. hongdoensis n. sp. is closely related to $P$. cortius de Laubenfels, 1930 in their spicules. However, they differ in kind and size of spicules and growth form. The dichotriaene rhabds of new species are larger than that of $P$. cortius. And the new species has oxyaster, but $P$. cortius has oxyspheraster. Although the growth forms of both species are irregular massive, this new species shows conspicuous long projection toward upper part.
\end{abstract}

Key words: Penares, Ancorinidae, Korea

\section{INTRODUCTION}

The genus Penares is characterized by irregularly massive, having dichotriaenes, oxeas, smooth microrhabds, centrotylote or not, forming a crust in the ectosome and euaster (Hooper and van Soest, 2002). The genus Penares is containing about 25 described species worldwide (van Soest, 2008). Three species of Penares have been reported from Korean waters (Kim et al., 1968; Sim, 1981). The present taxonomic study on marine sponge was based on the specimens collected by SCUBA from Hongdo Island, Korea in 2004. All procedures were followed the methods of Kim and Sim (2005) and Rützler (1978). The materials examined in this study were deposited in the Natural History Museum and Department of Biological Sciences, Hannam University, Daejeon, Korea.

\section{SYSTEMATIC ACCOUNTS}

Phylum Porifera Grant, 1836

Class Demospongiae Sollas, 1885

Order Astrophorida Sollas, 1888

Family Ancorinidae Schmidt, 1870

$1 *$ Penares hongdoensis n. sp. (Figs. 1-2)

Material examined. Holotype (Por. 95), Hongdo (Nammunbawi), Heuksan-myeon, Sinan-gun, Jeollanam-do, 9 September 2004, SCUBA diving $20 \mathrm{~m}$ deep, K.J. Lee, deposit-

\footnotetext{
*To whom correspondence should be addressed

Tel: 82-42-629-8755, Fax: 82-42-629-8751

E-mail: cjsim@hnu.kr
}

ed in HUNHM, Daejeon, Korea. Paratype (Por. 95-1), collected with holotype, deposited in the Department of Biological Sciences, Hannam University, Daejeon, Korea.

Description. Growth form irregular massive, size up to 7.5 $\times 5 \times 6 \mathrm{~cm}$. Texture slightly compressible. Surface smooth densely projection each projection $1-6 \mathrm{~cm}$ high, scattered numerous ostia. Oscules apical to each fistulose $0.5-1 \mathrm{~mm}$ in diameter. Colour dark gray in life which gradually changed to dark beige in alcohol. Ectosomal skeleton palisade with bicurvate microstrongyle. Choanosomal skeleton confused with dichotriaenes, oxeas and scattered oxyasters. Spicules, megascleres, oxea and dichotriaene. Microscleres, bicurvate microstrongyle and oxyaster.

Spicules.

Megascleres
Oxeas $\ldots \ldots \ldots \ldots \ldots \ldots \ldots \ldots \ldots \ldots \ldots \ldots \ldots \ldots \ldots$
Dichotriaenes $\ldots \ldots \ldots \ldots \ldots \ldots$ rhabds $560-1,300 \times 9-30 \mu \mathrm{m}$
clads $125-290 \times 40-50 \mu \mathrm{m}$

Table 1. The comparison of characters between $P$. hongdoensis n. sp. and $P$. cortius

\begin{tabular}{|c|c|c|}
\hline Characters Species & $\begin{array}{l}\text { P. hongdoensis } \\
\text { n. sp. }\end{array}$ & $\begin{array}{c}\text { P. cortius } \\
\text { de Laubenfels, } 1930\end{array}$ \\
\hline Growth form & Irregularly massive & Irregularly massive \\
\hline Colour & Dark gray & Beige \\
\hline \multicolumn{3}{|l|}{ Spicules $(\mu \mathrm{m})$} \\
\hline Oxeas & $650-1,300 \times 9-30$ & $950 \times 22$ \\
\hline \multicolumn{3}{|l|}{ Dichotriaene } \\
\hline Rhabds & $560-850 \times 37-50$ & $400 \times 50$ \\
\hline Clads & $125-290 \times 40-50$ & $310 \times 50$ \\
\hline Bicurvate microstrongyles & $50-160 \times 3-9$ & $50-160 \times 3-8$ \\
\hline Oxyasters & $20-40$ & Oxyspherasters $9-25$ \\
\hline
\end{tabular}

$1 *$ 홍도닺해면 (신칭) 


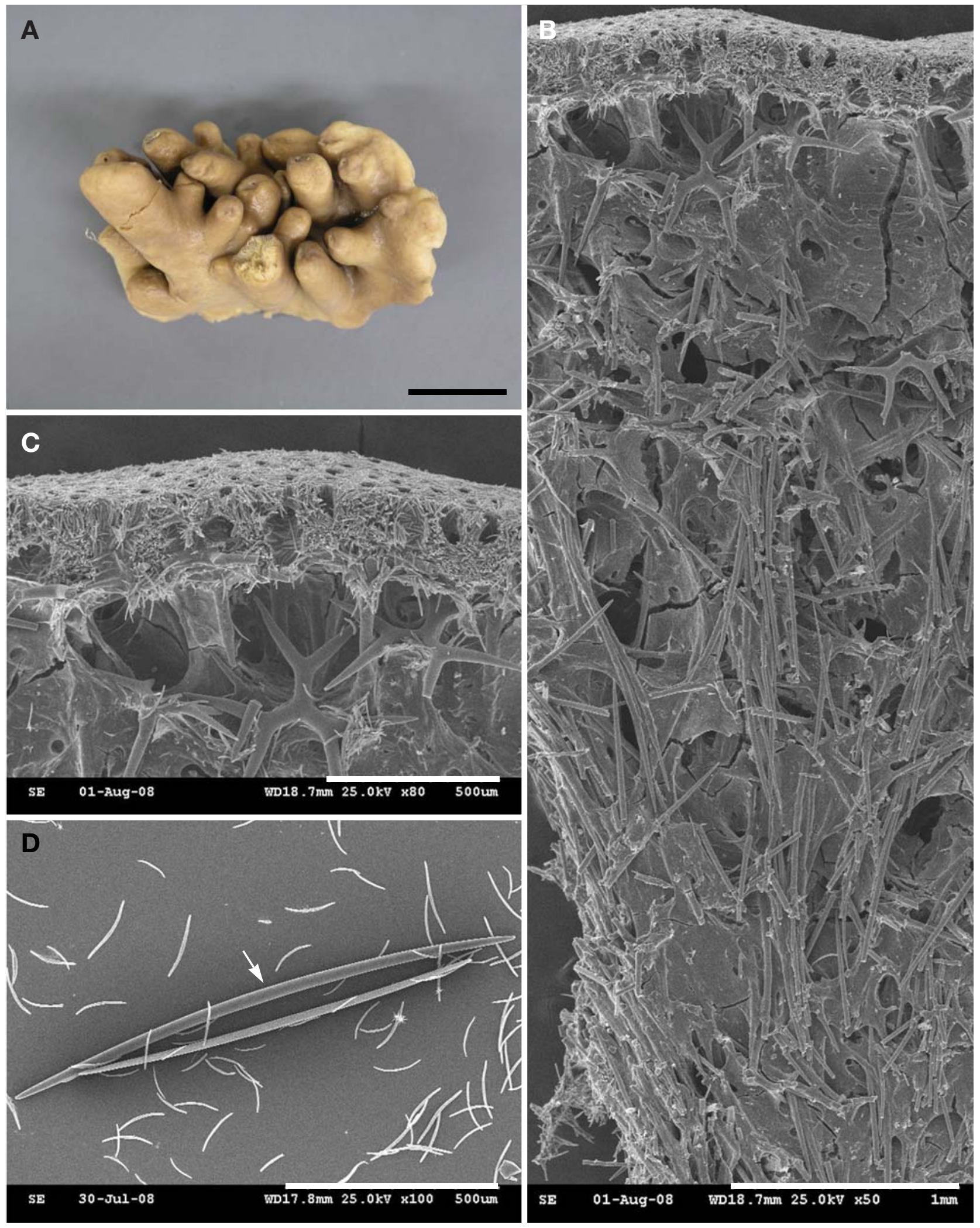

Fig. 1. Penares hongdoensis n. sp. A, entire animal; B, skeleton structure; C, ectosomal skeleton (palisade with microstrogyles); $D$, oxea (arrow). Scale bars $=2 \mathrm{~cm}(A), 1 \mathrm{~mm}(B), 500 \mu \mathrm{m}(C, D)$. 

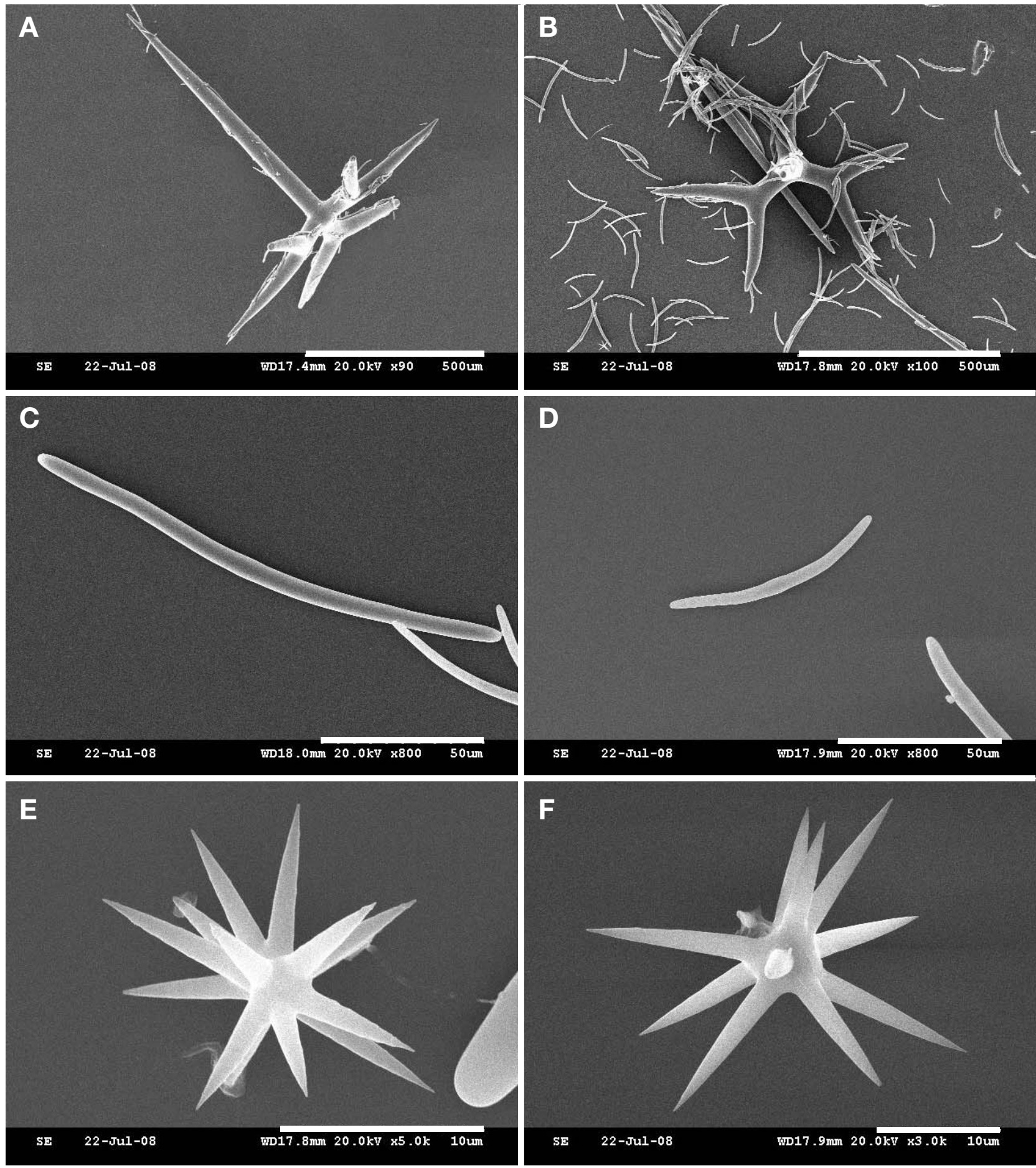

Fig. 2. Penares hongdoensis n. sp. A, dichotriaene; $B$, clad of dichotriaene; $C$, $D$, bicurvate microstrongyle; $E$, $F$, oxtyaster. Scale bars $=500 \mu \mathrm{m}(A, B), 50 \mu \mathrm{m}(C, D), 10 \mu \mathrm{m}(E, F)$.

\section{Microscleres}

Bicurvate microstrongyles $50-160 \times 3-9 \mu \mathrm{m}$

Oxyasters 20-40 $\mu \mathrm{m}$ Etymology. This species is named after the type locality,
Hongdo Island, Korea.

Remarks. $P$. hongdoensis $\mathrm{n}$. $\mathrm{sp}$. is closely related to $P$. cortius in their spicules. However, they differ in kind and size of spicules. The dichotriaene rhabd of new species is larger than 
that of $P$. cortius. And the new species has oxyaster, but $P$. cortius has oxyspheraster. Although the growth forms of both species are irregular massive, this new species shows conspicuous long projection towards upper part (Table 1).

\section{ACKNOWLEDGEMENTS}

This work was supported by a grant (no. 2007-491-1) from the Ministry of Environment of Korea Government.

\section{REFERENCES}

De Laubenfels, M.W., 1930. The sponges of California. (Abstracts of dissertations for the degree of doctor of philosophy) Stanford University Bulletin (5), 5(98): 24-29.

Hooper, J.N.A. and R.W.M van Soest, 2002. Systema Porifera. A Guide to the Classification of Sponges. Vol. 1. Kluwer
Academic/Plenum Publishers Press, USA, pp. 1-1101.

Kim, H.S., B.J. Rho and C.J. Sim, 1968. Marine sponges in south Korea (1). Korean J. Zool., 11(2): 37-48.

Kim, H.J. and C.J. Sim, 2005. Two new marine sponges of genus Clathria (Clathria) (Poecilosclerida: Microcionidae) from Korea. Korean J. Syst. Zool., 21(1): 111-122.

Rützler, K., 1978. Sponges in coral reefs. In Stoddart, D.R. and R.E. Johannes, eds., Coral Reefs: Research Methods. Monogr. Oceanogr. Neth. (UNESCO): 299-313.

Sim, C.J., 1981. A systematic study on the marine sponges in Korea. 1. Ceratinomorpha and Tetratinomorpha. Soong Jun Univ., 11: 83-105.

Soest, R.W.M. Van, Boury-Esnault, N., Hooper, J.N.A., Rützler, K., de Voogd, N.J., Alvarez, B., Hajdu, E., Pisera, A.B., Vacelet, J., Manconi, R., Schoenberg, C., Janussen, D., Tabachnick, K.R.M., Klautau, 2008. World Porifera database. Available online at http://www.marinespecies.org/porifera.

Received February 6, 2009 Accepted April 7, 2009 